\title{
Profile of acute childhood poisoning in South India: A prospective study
}

\author{
*Manjunath Vaddambal ${ }^{1}$, Balaji Prasad Yerneni ${ }^{1}$, Jagadishkumar $\mathbf{K}^{1}$
}

Sri Lanka Journal of Child Health, 2018; 47(4): 321-325

\begin{abstract}
Introduction: Childhood poisoning is a frequent cause of admissions to paediatric emergency wards.
\end{abstract}

Objective: To ascertain the major causative agents and mortality of childhood poisoning and to compare them with previous studies.

Method: A prospective observational study was conducted in JSS University Hospital, Mysore, India from November 2013 to April 2015. All children below 15 years of age with poisoning admitted to the paediatric ward were included. Those with food poisoning, snake bite and scorpion sting were excluded.

Results: A total of 105 children with poisoning below 15 years of age were admitted contributing to $1.58 \%$ of the total admissions. Majority of the cases $(84.7 \%)$ were below 5 years of age. Males constituted $58 \%$ of cases and $63 \%$ of cases were from rural areas. Accidental poisoning was the commonest mode seen in $90 \%$ of cases. Hydrocarbons $(32.4 \%)$, pesticides $(21.9 \%)$, drugs (20.9\%), and household compounds (18.09\%) were the offending agents. Kerosene poisoning alone contributed to $24.8 \%$ of cases. The commonest mode of presentation was vomiting seen in $59 \%$ of patients. While tachycardia (38.1\%) and tachypnoea (24.8\%), were commonly observed, more than half of the cases had no abnormal findings. One patient died due to organophosphorus poisoning giving a mortality rate of $0.95 \%$.

Conclusions: In this study $90 \%$ of poisoning in children were accidental in nature. Kerosene poisoning alone contributed to $25 \%$ of cases.

DOI: http://dx.doi.org/10.4038/sljch.v47i4.8593

(Key Words: Poisoning, children, kerosene)

${ }^{1}$ JSS Medical College, Mysore, India

*Correspondence: vghunsur@rediffmail.com

(Received on 29 January 2018: Accepted after revision on 16 March 2018)

The authors declare that there are no conflicts of interest

Personal funding was used for the project.

Open Access Article published under the Creative

Commons Attribution CC-BY (c) (i)

\section{Introduction}

Childhood poisoning is a frequent cause of admissions to paediatric emergency $\operatorname{wards}^{1}$. The global death rate from poisoning in persons below 20 years of age is 1.8 per 100000 population $^{2}$. It constitutes $0.33 \%-7.6 \%$ of total paediatric hospital admissions in India and mortality has ranged from $0.64-11.6 \%{ }^{3}$. While kerosene is the most common agent in developing countries, drugs, household products and pesticides are common agents in developed countries ${ }^{2}$. In a vast country like India, with regional differences in geographical and socio-economic background, there are variations in the types and frequency of childhood poisoning ${ }^{3}$.

\section{Objectives}

To ascertain the major causative agents and mortality of childhood poisoning and to compare them with previous studies.

\section{Method}

A prospective observational study was carried out from November 2013 to April 2015 at the department of paediatrics of JSS hospital, Mysore, India. All admitted childhood poisoning cases $<15$ years of age formed the study group. Children with snakebite, scorpion sting and food poisoning were excluded. The study was approved by the JSS hospital ethical committee. Consent was taken from the parents. All the relevant details were collected using a structured questionnaire. The patient's symptoms and signs present were noted along with, time of poisoning, place of poisoning, poison consumed, volume consumed, route of poisoning, circumstances of consumption and time of presentation. All cases were managed appropriately depending on the type of poisoning and severity. The descriptive statistics were done by measuring mean, median, standard deviation and proportions. The inferential statistics were done using Kruskal Wallis test. SPSS software version 21.0 was used for all measurements.

\section{Results}

During the study period a total of 105 children below 15 years of age with poisoning were admitted. Total cases admitted to paediatric department during the same period was 6624 . Out of these, poisoning cases constituted $1.58 \%$ of total admissions. Majority of the poisoning cases $(n=89$, $84.7 \%$ ) were below 5 years of age. Cases both below 1 year and above 5 years of age constituted $15.2 \%$ each. The incidence of poisoning cases was higher among males $(58.1 \%)$ than females $(41.9 \%)$. 
About $63.8 \%$ of poisoning cases hailed from rural areas as compared to $36.2 \%$ from urban areas (Table 1).

Table 1: Demographic characteristics of poisoning in children $(n=105)$

\begin{tabular}{|l|c|}
\hline \multicolumn{1}{|c|}{ Variable } & Number (\%) \\
\hline Age group & $16(15.2)$ \\
$<1$ year & $56(53.3)$ \\
$1-<3$ years & $17(16.2)$ \\
$3-<5$ years & $11(10.5)$ \\
$5-10$ years & $05(04.8)$ \\
$>10$ years & \\
\hline Gender & $61(58.1)$ \\
Male & $44(41.9)$ \\
Female & \\
\hline Locality & $38(36.2)$ \\
Urban & $67(63.8)$ \\
Rural & \\
\hline Method of poisoning & $95(90.4)$ \\
Accidental & $05(04.8)$ \\
Suicidal & $04(03.8)$ \\
Homicidal & $01(01.0)$ \\
Experimental & \\
\hline
\end{tabular}

The commonest mode of poisoning was accidental $(90.4 \%)$ (Table 1). All the suicidal cases were observed in the age group of 11-15 years.

The distribution of type of poisoning is shown in Table 2.

Hydrocarbon class of compounds constituted the biggest chunk of cases followed by pesticides, drugs and household compounds (Table 2). In the miscellaneous group, fire-cracker poisoning and nut poisoning were commonest followed by ingestion of surgical spirits, castor seeds and unidentified seeds. Among hydrocarbons, kerosene was the commonest offending agent. Among pesticides, pyrethroids organophosphate and zincphosphide were commonly involved. Benzodiazepines and antipsychotics were the drugs being commonly involved. Corrosives (acid) and Eucalyptus oil were the common household items (Table 2).
Table 2: Distribution of type of poisoning $(n=105)$

\begin{tabular}{|l|c|}
\hline \multicolumn{1}{|c|}{ Poison category } & Number (\%) \\
\hline Hydrocarbon & $\mathbf{3 4}(\mathbf{3 2 . 4 )}$ \\
Kerosene & $26(24.8)$ \\
Thinner & $07(06.6)$ \\
Petrol & $01(01.0)$ \\
\hline Drugs & $\mathbf{2 2}(\mathbf{2 0 . 9 )}$ \\
Benzodiazepine & $03(02.9)$ \\
Risperidone & $02(01.9)$ \\
Paracetamol & $02(01.9)$ \\
*Others & $15(14.1)$ \\
\hline Pesticides & $\mathbf{2 3}(\mathbf{2 1 . 9 )}$ \\
Pyrethroids & $13(12.4)$ \\
Organophosphates & $05(04.8)$ \\
Zinc phosphide & $04(03.8)$ \\
Organochlorine & $01(01.0)$ \\
\hline Household & $\mathbf{1 9}(\mathbf{1 8 . 1})$ \\
Corrosive (acid) & $06(05.7)$ \\
Eucalyptus oil & $05(04.9)$ \\
Camphor & $04(03.8)$ \\
Corrosive (alkali) & $01(01.0)$ \\
Fabric whitener & $01(01.0)$ \\
Chalk lime & $01(01.0)$ \\
Shikakhai powder & $01(01.0)$ \\
\hline Miscellaneous & $\mathbf{0 7}(\mathbf{0 6 . 7 )}$ \\
\hline Others: Gamma & benzene, \\
\hline
\end{tabular}

*Others: Gamma benzene, lead, telmisartan, levosalbutamol, levocetirizine, ofloxacin, cyproheptadine, moxonidine, iron, montelukast, cetirizine, amitryptiline, thyroxine, deriphylline, ondansetron, olanzapine, unknown---one each

The route of poisoning was ingestion in all cases. The mean time lapse before reaching hospital was 7.29 hours and time lapse was greatest (11.27 hours) in the hydrocarbon group. First aid management was given in $33.3 \%$ (stomach wash $26.6 \%$ and activated charcoal $6.7 \%$ ) of patients who directly came to our hospital within one hour of ingestion. Vomiting was the commonest symptom (59\%) followed by cough (19\%), lethargy $(12.4 \%)$ and hurried breathing (11.4\%). About $19 \%$ of cases were asymptomatic (Table 3 ). 
Table 3: Clinical features of poisoning in the study group $(n=105)$

\begin{tabular}{|l|c|l|c|}
\hline \multicolumn{1}{|c|}{ Symptom } & Number (\%) & \multicolumn{1}{c|}{ Sign } & Number (\%) \\
\hline Vomiting & $62(59.0)$ & Normal & $56(53.3)$ \\
\hline Cough & $20(19.0)$ & Tachycardia & $40(38.1)$ \\
\hline Drowsiness lethargy & $13(12.4)$ & Tachypnoea & $26(24.8)$ \\
\hline Hurried breathing & $12(11.4)$ & RS involvement & $19(18.1)$ \\
\hline Convulsions & $07(06.7)$ & CNS involvement & $15(14.3)$ \\
\hline Loose stools & $06(05.7)$ & Smell of compound & $07(06.7)$ \\
\hline Fever & $06(05.7)$ & Fever & $06(05.7)$ \\
\hline Pain in abdomen & $05(04.8)$ & Low SpO2 (<93) & $03(02.9)$ \\
\hline Hoarseness of voice & $02(01.9)$ & Hypotension & $02(01.9)$ \\
\hline Tremors & $02(01.9)$ & Prolonged CFT & $02(01.9)$ \\
\hline Refusal of feeds & $01(01.0)$ & CVS involvement & $02(01.9)$ \\
\hline Excessive cry & $01(01.0)$ & GIT involvement & --------- \\
\hline Headache & $01(01.0)$ & ------------ & . \\
\hline
\end{tabular}

RS: respiratory system, CNS: central nervous system, SpO2: oxygen saturation, CFT: capillary filling time, CVS: cardiovascular system, GIT: gastrointestinal tract

Clinical examination at admission was normal in more than half the number of cases. Abnormal findings observed commonly were tachycardia, tachypnoea, respiratory involvement and central nervous system involvement (Table 3). Ingested agents (poison) were smelt by the clinician in $12.4 \%$ of cases (Table 3 ).

Out of the 105 cases, one child with organophosphorus poisoning died (Table 4).

Table 4: Outcome of poisoning $(n=105)$

\begin{tabular}{|l|c|}
\hline \multicolumn{1}{|c|}{ Outcome } & Number (\%) \\
\hline Discharged & $93(88.6)$ \\
\hline $\begin{array}{l}\text { Discharged against medical } \\
\text { advice }\end{array}$ & $11(10.5)$ \\
\hline Death & $01(0.95)$ \\
\hline
\end{tabular}

\section{Discussion}

Due to the curiosity of children, poisonous substances are often inadvertently ingested by them in the home and its surroundings ${ }^{2}$. Poisoning is a significant cause of morbidity and mortality in paediatric patients, worldwide ${ }^{2}$. It is responsible for $0.3 \%$ to $7.6 \%$ of total admissions in paediatric department at various hospitals across India ${ }^{3,4}$. In the present study poisoning accounted for $1.4 \%$ of admissions in our paediatric ward.

We observed that poisoning was most common in children in the age group of 1-3 years and similar observations were made by others ${ }^{3-5}$. Young children because of their inherent curiosity, close proximity to the ground and tendency to put things in their mouths are frequently subject to accidental poisoning ${ }^{4}$. Poisoning death rates are highest in infants, while non-fatal poisoning seems to be commoner in 1-4 year old children ${ }^{2}$. However, in a study by Sharma et al $76.5 \%$ of cases were aged between 11-18 years ${ }^{6}$. We observed male predominance which is a common feature in most series $^{3,4,6}$. Poisoning is commoner in boys than girls all over the world ${ }^{2}$. However, females $(51.6 \%)$ were more commonly affected compared to males in a study conducted by Sahin et al from Turkey ${ }^{1}$.

The majority of our patients were rural natives as our hospital caters to a large rural area which is similar to studies from North India ${ }^{7,8}$. Studies by Surjit Singh et al and Gupta et al showed higher urban proportion of $72.3 \%$ and $61.6 \%$ respectively ${ }^{5,9}$. The common method of poisoning in our study was accidental (90.6\%) which is similar to many other studies ${ }^{4,8}$. In a review of 10 years data from North India accidental poisoning accounted for $78 \%$ of cases 5 . However, Jose et al reported suicidal mechanism to be the commonest accounting for $70.2 \%$ of $\operatorname{cases}^{10}$. In a study by Aziz et al, 56.9\% cases were suicidal, 39.2\% were accidental and $3.9 \%$ cases were homicidal ${ }^{11}$. They also reported that all poisoning in children less than 12 years of age were accidental while it was suicidal in the majority of cases between 12-18 years of age ${ }^{11}$. All the suicidal cases in the present study were observed in the age group of 11-15 years showing the preponderance of adolescents to suicide. One of our 12 year old boys tried to experiment the effect of drug by ingesting risperidone tablets which was prescribed for his grandfather.

Majority of poisoning was due to hydrocarbons, drugs, insecticides and household products in our study which is similar to study done by Kohli et al and Rathore et $a l^{4,12}$. A ten year study from Chandigarh also revealed kerosene as one of the common agent accounting for $25 \%$ of all poisoning cases $^{5}$. Even with the increasing usage of liquid petroleum gas (LPG) for cooking and availability of electricity in rural areas, we found in our study kerosene to be the major cause of accidentally ingested poison. Similar to our study Lucas from Sri Lanka also concluded that rural people store 
kerosene in empty soft-drink bottles and keep within easy reach for the young child playing on the floor ${ }^{13}$. As evident from the few studies from North India, the incidence of kerosene poisoning has dropped over the years with increasing use of LPG and availability of electricity even in rural areas $^{3,5}$. Even in countries like Pakistan and Sri Lanka kerosene is the common agent of poisoning accounting for $50 \%$ and $36 \%$ of cases respectively ${ }^{13,14}$. However, Sharma et al observed only $4.9 \%$ of their cases were due to kerosene poisoning while majority were insecticide poisoning cases ${ }^{6}$. They explain that this may be due to most of their cases being in the age group of 1115 years and majority from rural areas where insecticides are routinely kept in houses.

We observed drugs as offending agents in $26 \%$ with sedatives and antidepressants being commonly implicated. However, drugs accounted for more than half the cases of poisonings in developed countries ${ }^{13}$. Data from national poisons information centre, AIIMS, New Delhi reveals that of the total 995 poisoning cases in children below 18 years of age, $21.7 \%$ were due to drugs ${ }^{15}$.

Pesticides accounted for $21 \%$, in that more than half of them were due to pyrethroids in the present study. Lucas also reported ingestion of mosquito coils in $6 \%$ of cases in Sri Lanka ${ }^{13}$. Pyrethroids, mosquito repellents are used extensively in India because of the fear of dengue which has become an important cause of childhood mortality. Fortunately their toxicity is low because of poor absorption from the gut ${ }^{13}$. Poisoning due to organophosphorus compounds was observed in 5 children and all of them were from rural areas. Organophosphates were the commonest offending agent in various other studies ${ }^{7,8,16}$. Camphor and eucalyptus oil are used commonly in most Indian households and if ingested can affect central nervous system causing status epilepticus and death.

Common symptoms in our study were vomiting $(59 \%)$, cough $(19 \%)$ lethargy $(12.4 \%)$ and hurried breathing $(11.4 \%)$ in the order of decreasing frequency. Vomiting is also the commonest symptom in most other studies ${ }^{4,16}$. In more than $50 \%$ of cases in our study there were no signs.

The mortality in childhood poisoning ranges from 0 to $11.6 \%$ in India, whereas in Pakistan it is 2.5 $13.6 \% 3,4,14$. A study from Sri Lanka had $0.7 \%$ mortality ${ }^{13}$. We observed death in one child due to organophosphorus poisoning which accounted for $0.95 \%$ mortality. While Kohli et al reported no deaths in their study and Sharma et al reported a mortality rate of $6 \%$ in their cases ${ }^{4,6}$. In a study from Chandigarh overall mortality was $12.5 \%$ and all deaths were in the age-group of 11-15 years and were mostly due to consumption of aluminium phosphide which has no specific antidote ${ }^{5}$. In some countries poisoning death rates are highest in infants, while non-fatal poisoning seems to be commoner in children 1 to 4 years old ${ }^{2}$.

Kerosene is the main substance responsible for accidental poisoning in children as this is neither sold in proper containers nor stored properly in households. Educating parents regarding storage of medicines and common household chemicals will reduce this preventable cause of childhood morbidity and mortality.

\section{Conclusions}

In this study $90 \%$ of poisoning in children were accidental in nature. Kerosene poisoning alone contributed to $25 \%$ of cases.

\section{References}

1. Sahin S, Carman KB, Dinleyici EC. Acute poisoning in children; data of a paediatric emergency unit. Iran Journal of Pediatrics 2011; 21:479-84.

PMid: 23056835 PMCid: PMC3446134

2. Peden M, Oyegbite K, Joan Ozanne-Smith J, Hyder AA, Branche C, Fazlur Rahman AKM et al. editors, World report on child injury prevention. World Health Organization 2008.

3. Dutta AK, Seth A, Goyal PK, Agarwal V, Mittal SK, Sharma R et al. Poisoning in children, Indian scenario. Indian Journal of Pediatrics 1998; 65:365-70. https://doi.org/10.1007/BF02761129 PMid: 10771987

4. Kohli U, Kuttiat VS, Lodha R, Kabra SK. Profile of childhood poisoning at a tertiary care centre in North India. Indian Journal of Pediatrics 2008; 75:791-4. https://doi.org/10.1007/s12098-008-01057

PMid: 18581069

5. Singhi S, Sood NK, Kumar L, Walia BNS. Changing pattern of childhood poisoning (1970-1989): Experience of a large North Indian hospital. Indian Pediatrics 1995; 32:333-6.

6. Sharma J, Kaushal RK, Profile of poisoning in children. Pediatric Oncall [serial online] 2014[cited 2014 April-June 1]; Available from: 
http://www.pediatriconcall.com/pediatricjournal/View/fulltextarticles/828/J/0/0/439/0

7. Ramdev S, Grover N, Sharma R, Sharma $\mathrm{H}$. Acute poisoning in children: seven year experience at a tertiary care hospital of North India. Current Paediatric Research 2011; 15:65-8.

8. Bhat NK, Dhar M, Ahmad S, Chandar V. Profile of poisoning in children and adolescents at a north Indian tertiary care centre. Journal, Indian Academy of Clinical Medicine 2012; 13:37- 42.

9. Gupta S, Govil YC, Misra PK, Nath R, Srivastava KL. Trends in poisoning in children: experience at a large referral teaching hospital. National Medical Journal of India 1998; 11: 166-8. PMid: 9808971

10. Jose A, Sivanandam, Matthai J. Poisoning in children from an educationally and economically advanced urban area of south India. Asian Journal of Epidemiology 2012; 5:123-9.

https://doi.org/10.3923/aje.2012.123.129

11. Abdul Aziz UB, Aslami AN, Ali SM. Profile of acute paediatric poisoning cases admitted in a tertiary care centre in North India. Indian Journal of Forensic Medicine \& Toxicology 2016; 10:217-21. https://doi.org/10.5958/09739130.2016.00 050.5
12. Rathore S, Verma AK, Pandey A, Kumar S. Paediatric poisoning trend in Lucknow District, India. Journal of Forensic Research 2013; 4:179.

13. G N Lucas. A hospital based prospective study of acute childhood poisoning. Sri Lanka Journal of Child Health 2006; 35: 12-19.

https://doi.org/10.4038/sljch.v35i1.3

14. Manzar N, Saad SMA, Manzar B, Fatima SS. The study of aetiological and demographic characteristics of acute household accidental poisoning in children - a consecutive case series study from Pakistan. BMC Pediatrics 2010; 10:28. https://doi.org/10.1186/1471-2431-10-28 PMid: 20438635 PMCid: PMC2873520

15. Gupta SK, Peshin SS, Srivastava A, Kaleekal T. A study of childhood poisoning at National Poisons Information Centre, All India Institute of Medical Sciences, New Delhi. Journal of Occupational Health 2003; 45: 191-6. https://doi.org/10.1539/joh.45.191 PMid: 14646297

16. Bhudhatoki S, Poudel P, Shah D, Bhatta NK, Dutta AK, Shah GS et al. Clinical profile and outcome of children presenting with poisoning or intoxication: a hospital based study. Nepal Medical College Journal 2009; 11(3):170-5. 